\title{
Correction to: Twenty-five years of adaptation finance through a climate justice lens
}

\section{Mizan Khan ${ }^{1} \cdot$ Stacy-ann Robinson ${ }^{2}$ (D) $\cdot$ Romain Weikmans $^{3}$ (D) David Ciplet $^{4}$. J. Timmons Roberts ${ }^{5}$}

Published online: 8 January 2020

(C) Springer Nature B.V. 2020

\section{Correction to: Climatic Change https://doi.org/10.1007/s10584-019-02563-x}

The original article has been updated. Unfortunately the uncorrected version of the article was published online. This has been corrected.

The online version of the original article can be found at https://doi.org/10.1007/s10584-019-02563-x

Stacy-ann Robinson smrobins@colby.edu

\section{J. Timmons Roberts} timmons@brown.edu

Mizan Khan

mizan.khan@icccad.net

Romain Weikmans

eromain.weikmans@ulb.be

David Ciplet

david.ciplet@colorado.edu

1 LDC Universities Consortium on Climate Change (LUCCC), International Centre for Climate Change and Development (ICCCAD), Dhaka, Bangladesh

2 Environmental Studies Program, Colby College, Waterville, ME 04901, USA

3 Institute for Environmental Management and Land Use Planning, Université Libre de Bruxelles, Brussels, Belgium

4 Department of Environmental Studies, University of Colorado-Boulder, Boulder, CO 80303, USA

5 Institute at Brown for Environment and Society, Brown University, Providence, RI 02912, USA 